\title{
Analysis of generalized continual-clamp and split-clamp PWM schemes for induction motor drive
}

\author{
SOUMITRA DAS ${ }^{1, *}$,, V S S PAVAN KUMAR HARI ${ }^{2}$, ARUN KUMAR $^{3}$ and G NARAYANAN ${ }^{4}$ \\ ${ }^{1}$ Department of Electrical and Electronics Engineering, National Institute of Technology Goa, Goa 403401, \\ India \\ ${ }^{2}$ Department of Energy Science and Engineering, Indian Institute of Technology Bombay, Mumbai 400076, \\ India \\ ${ }^{3} 3$ rd floor, P'DMello Road, Wadibunder, Mumbai 400010, India \\ ${ }^{4}$ Department of Electrical Engineering, Indian Institute of Science, Bangalore 560012, India \\ e-mail: soumitradas81@gmail.com; pavanhari@iitb.ac.in; arun620686@gmail.com; gnar@iisc.ac.in
}

MS received 9 May 2017; accepted 6 September 2018; published online 25 January 2019

\begin{abstract}
Continual-clamp pulse width modulation (CCPWM) clamps each phase of a three-phase inverter to one of the two dc buses continually for $60^{\circ}$ duration in each half of the fundamental cycle. Split-clamp pulse width modulation (SCPWM) divides the $60^{\circ}$ clamping interval into two sub-intervals, which are not necessarily equal, and falling in two different quarter cycles. Whether continual clamp or split clamp, the positioning of the clamping interval in case of CCPWM, and the ratio of splitting the clamping interval in SCPWM - all influence the waveform quality of the inverter output. This paper derives analytically closed-form expressions for the total RMS harmonic distortion factor and torque ripple factor pertaining to CCPWM with any arbitrary position of the clamping interval (i.e., generalized CCPWM) and also corresponding to SCPWM with any arbitrary ratio of splitting of the clamping interval (i.e., generalized SCPWM). The analytical results are well supported by experimental results on 3-hp and 5-hp induction motor drives.
\end{abstract}

Keywords. Analytically derived closed-form expression; bus-clamping pulse width modulation; continualclamp PWM; discontinuous PWM; harmonic analysis; harmonic distortion; split-clamp PWM; pulsating torque; voltage source inverter; waveform quality.

\section{Introduction}

Research on bus-clamping pulse width modulation (BCPWM) strategies [1] for three-phase voltage source inverter (see figure 1) started a few decades back [1-6], has continued over the last two decades [7-22] and remains active even at present [23-32]. A number of pulse width modulation (PWM) schemes were proposed in the early years of research on BCPWM [1-6]. Though these PWM schemes are seemingly different, all these methods clamp each phase to the positive or negative dc bus during different intervals in a line cycle; hence the name busclamping PWM [1]. Since one of the phases is clamped and only two phases switch in any carrier cycle with these PWM methods, they are also sometimes referred to as twophase modulation $[8,9]$. The modulating signals used by such schemes are discontinuous functions of time, as illustrated in figure 2(a) and 2(b). Hence such methods are more commonly known as discontinuous pulse width modulation (DPWM) methods [10, 11].

*For correspondence
The modulating signal in figure 2(a) is one of the early bus-clamping modulation signals [2]. As seen from figure 2 (a), the clamping for a phase occurs in the middle $60^{\circ}$ duration of each voltage half-cycle; hence the name $60^{\circ}$ clamp PWM for this method [17, 19]. Figure 2(b) illustrates the modulating signal corresponding to another popular BCPWM method where the clamping occurs in the middle $30^{\circ}$ of each voltage quarter cycle. This technique is termed $30^{\circ}$ clamp PWM [17, 19].

More generally, the $60^{\circ}$ clamping duration in figure 2(a) can be positioned anywhere within the middle $120^{\circ}$ of the voltage half-cycle, i.e., $\left(30^{\circ}+\gamma\right)$ to $\left(90^{\circ}+\gamma\right)$, where $0^{\circ} \leq \gamma \leq 60^{\circ}$. This technique is referred to as continual clamp PWM (CCPWM) [17, 21, 22]. Similarly, the $60^{\circ}$ clamping interval could be split into two intervals of $\gamma$ and $\left(60^{\circ}-\gamma\right)$, positioned in the first and second quarter cycles, respectively, in each half cycle. This method is termed split clamp PWM (SCPWM) [17, 21, 22].

CCPWM with any general $\gamma$ has been studied extensively, particularly in the context of reduction in inverter switching loss when feeding high power factor loads $[11,14]$. Effect of the positioning of the clamping interval 


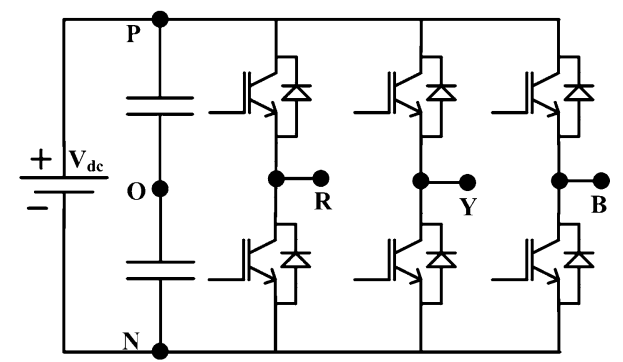

Figure 1. Power circuit diagram of a two-level inverter.
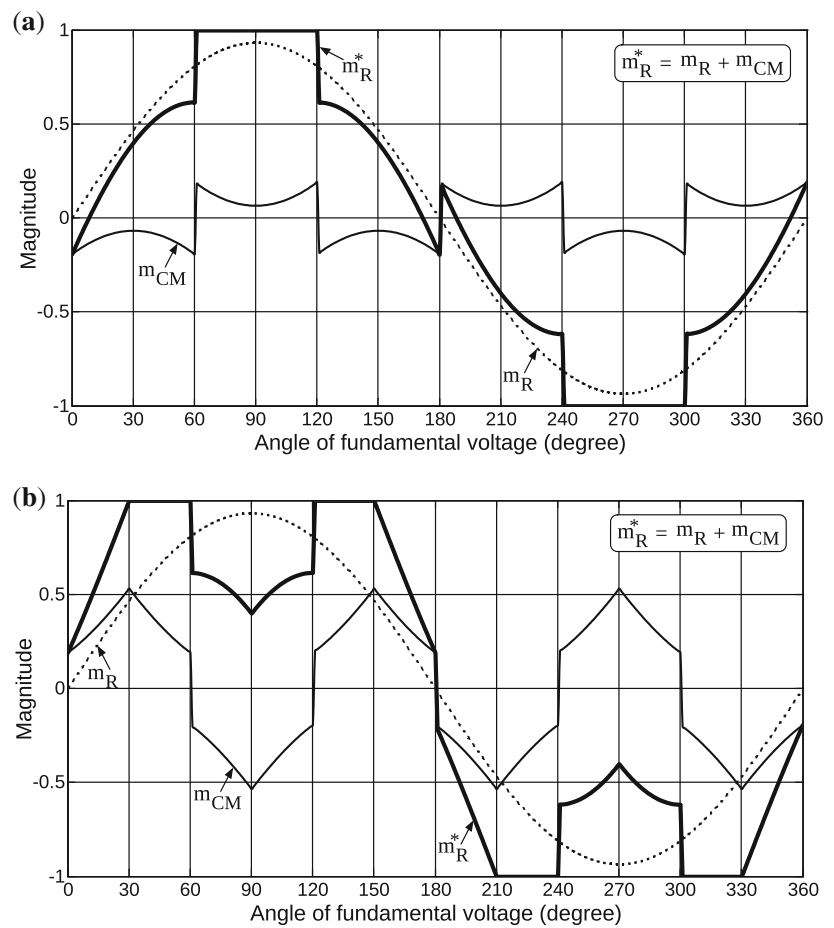

Figure 2. Popular BCPWM schemes: (a) $60^{\circ}$ clamp PWM [2] and (b) $30^{\circ}$ clamp PWM [6].

on total harmonic distortion (THD) in line current has been studied only for specific values of $\gamma$ (i.e., $0^{\circ}, 30^{\circ}, 60^{\circ}$ ) $[5,8,11,21]$. To the best of authors' knowledge, the influence of this positioning on torque ripple in an induction motor drive has not been reported. One objective here is to investigate the effect of the optimal positioning (i.e., $\gamma=\gamma_{\text {opt }}$ ) and/or any arbitrary positioning (i.e., $0^{\circ} \leq \gamma \leq 60^{\circ}$ ) of the clamping interval in CCPWM on motor current THD and pulsating torque.

Also, despite the long history of BCPWM $[1-5,10,11,14]$, the study of SCPWM (other than $\gamma=30^{\circ}$ ) is relatively rare and recent $[17,21,22,24]$. The focus of these papers is to investigate the reduction in switching loss due to unequal splitting of the clamping interval and to arrive at the optimal splitting to minimize switching loss.
The effects of such unequal and/or optimal splitting of the clamping interval in SCPWM on both THD and pulsating torque are studied in the present paper.

Harmonic distortion factor is widely used for comparative evaluation of line current THD from different PWM methods, regardless of machine or line-side parameters $[8,11,16]$. Closed-form expressions have been derived analytically for harmonic distortion factors pertaining to specific PWM methods [8, 11, 16, 21, 33].

This paper attempts to derive analytically closed-form expressions for two classes of PWM methods, namely, CCPWM with any arbitrary $\gamma$, and SCPWM with any arbitrary $\gamma$ (i.e., $0^{\circ} \leq \gamma \leq 60^{\circ}$ ). The paper also derives analytically closed-form expressions for torque ripple factor [33], pertaining to the two classes of PWM methods. The torque ripple factor is a measure of torque ripple produced by the motor and is independent of motor parameters [33]. The analytical results are well supported by experimental results from 3-hp and 5-hp induction motor drives.

\section{CCPWM and SCPWM schemes}

Generation of common-mode and modulating signals for CCPWM and SCPWM is illustrated in figure 3. Optimal CCPWM [11, 17, 22] and optimal SCPWM [17, 22] to minimize inverter switching loss are reviewed.

\subsection{Modulating waves}

Three-phase sinusoidal signals $m_{R}, m_{Y}$ and $m_{B}$ are shown in figures 3(a) and (b). Based on the maximum among these signals, the common-mode signal $m_{C M} \_$, which can clamp one of the phases to positive dc buses, can be generated as given in eq. (1a), and shown in figure 3(a).

$$
\begin{gathered}
m_{C M \_P}=1-\max \left(m_{R}, m_{Y}, m_{B}\right), \\
m_{C M \_N}=-1-\min \left(m_{R}, m_{Y}, m_{B}\right) .
\end{gathered}
$$

Similarly, using eq. (1b), the common-mode signal $m_{C M \_N}$ to clamp a phase to the negative dc bus can be obtained as illustrated in figure 3(b).

As known widely [11], the common-mode signal $m_{C M \_C C}$ for CCPWM can be expressed as

$$
m_{C M \_C C}=\left\{\begin{array}{c}
m_{C M \_P},\left(30^{\circ}+\gamma\right)<\omega t<\left(90^{\circ}+\gamma\right), \\
m_{C M \_N},\left(90^{\circ}+\gamma\right)<\omega t<\left(150^{\circ}+\gamma\right) .
\end{array}\right.
$$

The common-mode signal $m_{C M \_S C}$ for SCPWM can be obtained by swapping $m_{C M \_P}$ and $m_{C M_{-} N}$ in the two sets of intervals as shown:

$$
m_{C M \_S C}=\left\{\begin{array}{l}
m_{C M \_N},\left(30^{\circ}+\gamma\right)<\omega t<\left(90^{\circ}+\gamma\right), \\
m_{C M \_P},\left(90^{\circ}+\gamma\right)<\omega t<\left(150^{\circ}+\gamma\right) .
\end{array}\right.
$$




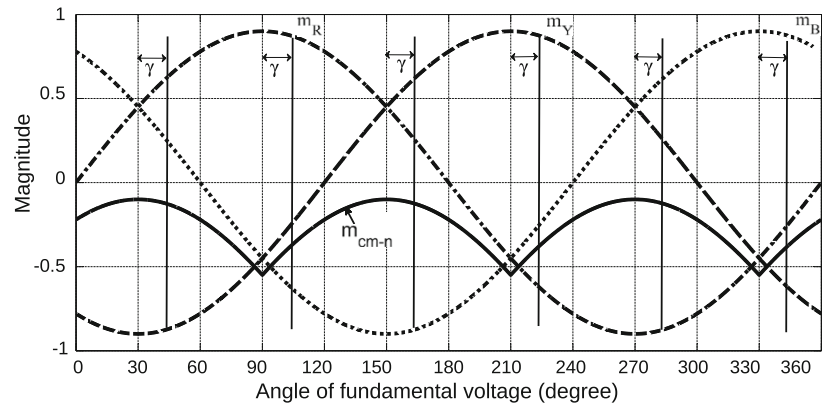

(a)

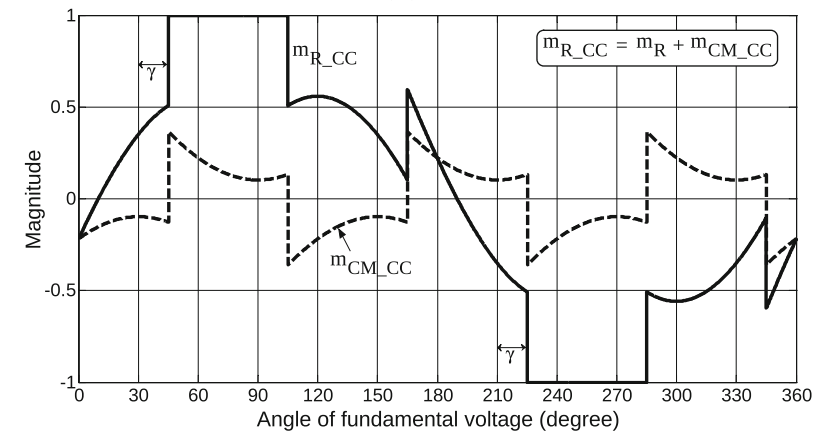

(c)

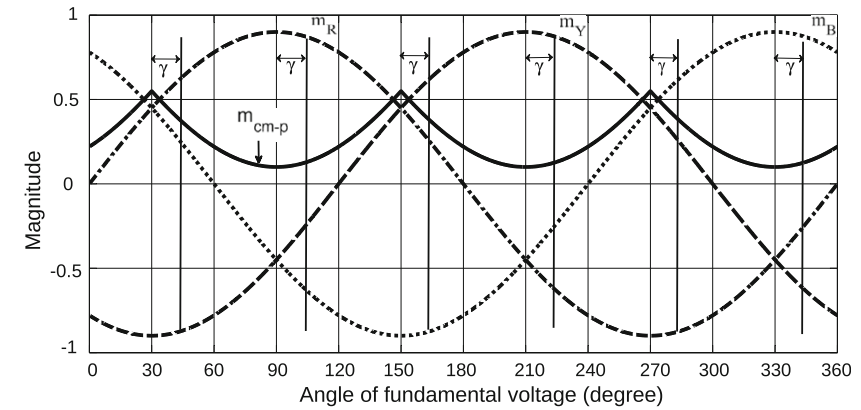

(b)

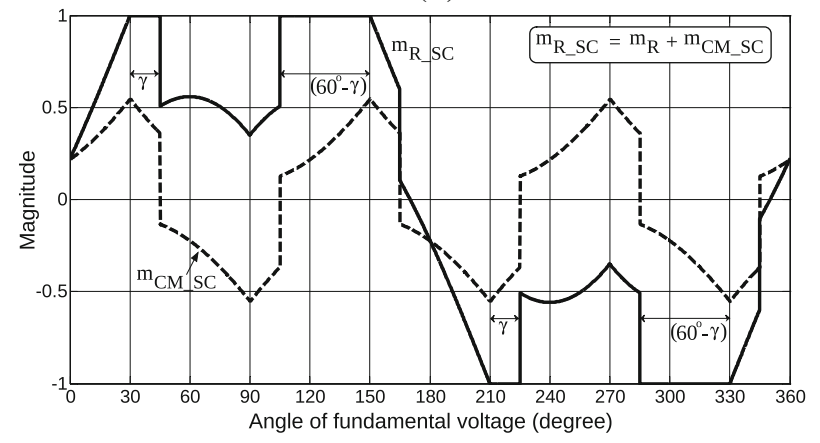

(d)

Figure 3. (a) Positive common-mode signal, (b) negative common-mode signal, (c) modulating signal and common-mode signal for CCPWM and (d) modulating signal and common-mode signal for SCPWM.

The modulating signals for CCPWM and SCPWM, $m_{R} \_C C$ and $m_{R} S_{S C}$, obtained by adding the respective commonmode signals $m_{C M} \_C C$ and $m_{C M} \_S C$ to the sinusoidal signal $m_{R}$, are shown in figures 3(c) and (d). The clamping regions of R-phase with CCPWM and SCPWM depend on the parameter $\gamma$ as indicated in table 1 [21].

As will be shown in later sections, a typical modulating signal shown in figure 3(d) is better than a typical modulating signal as in figure 3(c) both in terms of harmonic distortion and pulsating torque.

\subsection{Optimal CCPWM and optimal SCPWM}

The optimal value of $\gamma$ (i.e., $\gamma_{o p t}$ ) to minimize the inverter switching loss with CCPWM depends on the power factor angle $\phi$ as shown in dotted line in figure 4(a). CCPWM with $\gamma=\gamma_{\text {opt }}$ is referred to as optimal continual clamp PWM (OCCPWM). Similarly, optimal split clamp PWM

Table 1. Clamping Regions of R-Phase with CCPWM and SCPWM.

\begin{tabular}{lc}
\hline Schemes & Clamping regions of R-phase \\
\hline CCPWM & $\left(30^{\circ}+\gamma\right)<\omega t<\left(90^{\circ}+\gamma\right)$ \\
& $\left(210^{\circ}+\gamma\right)<\omega t<\left(270^{\circ}+\gamma\right)$ \\
SCPWM & $30^{\circ}<\omega t<\left(30^{\circ}+\gamma\right) ;\left(90^{\circ}+\gamma\right)<\omega t<150^{\circ}$ \\
& $210^{\circ}<\omega t<\left(210^{\circ}+\gamma\right) ;\left(270^{\circ}+\gamma\right)<\omega t<330^{\circ}$ \\
\hline
\end{tabular}

(OSCPWM) employs $\gamma=\gamma_{\text {opt }}$, which varies with $\phi$ as shown by the solid line in figure 4(a).

The switching loss from different PWM methods, normalized with respect to that from the conventional space vector PWM (CSVPWM), is shown plotted against power factor angle in figure 4(b). The switching energy loss is assumed to be proportional to the fundamental current here. The BCPWM methods are compared at the same average switching frequency (or carrier frequency equal to 1.5 times that of conventional space vector PWM) $[17,22]$.

It can be seen from figure $4(\mathrm{~b})$ that the $60^{\circ}$ clamp PWM (curve 2) reduces the switching loss significantly at high power factors, but increases the loss at low power factors, compared with CSVPWM. The $30^{\circ}$ clamp PWM (curve 3) results in a marginally lower switching loss than CSVPWM at high and low power factors, but there is a marginal increase in switching loss with this method over CSVPWM at medium power factors. OCCPWM (curve 4) yields lower switching loss than CSVPWM over a wide range of power factor, though still not close to that of zero power factor. OSCPWM (curve 5) results in a lower switching loss than CSVPWM over the whole range of power factor [17].

Thus, whether CCPWM or SCPWM, variation of $\gamma$ in accordance with power factor is beneficial from a switching loss perspective. This paper examines the effect of such variation of $\gamma$ on line current distortion and torque ripple. 


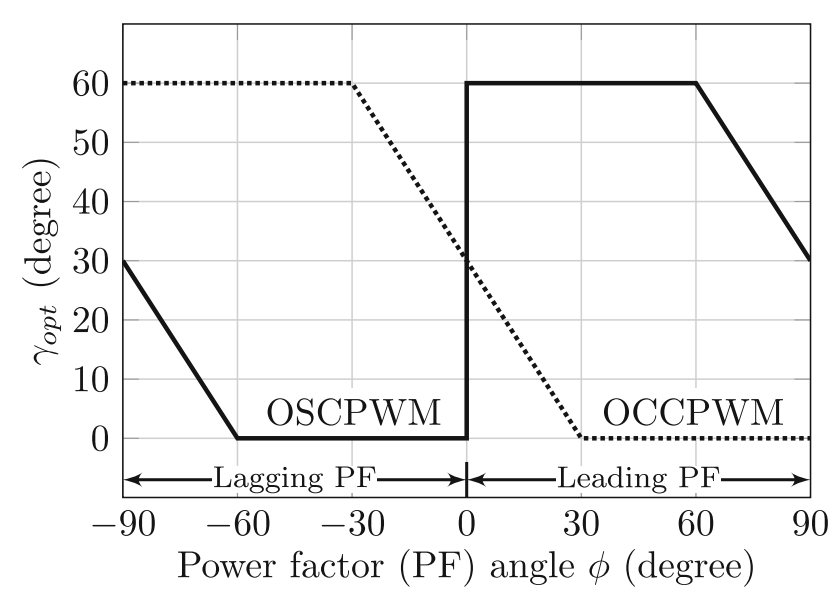

(a)

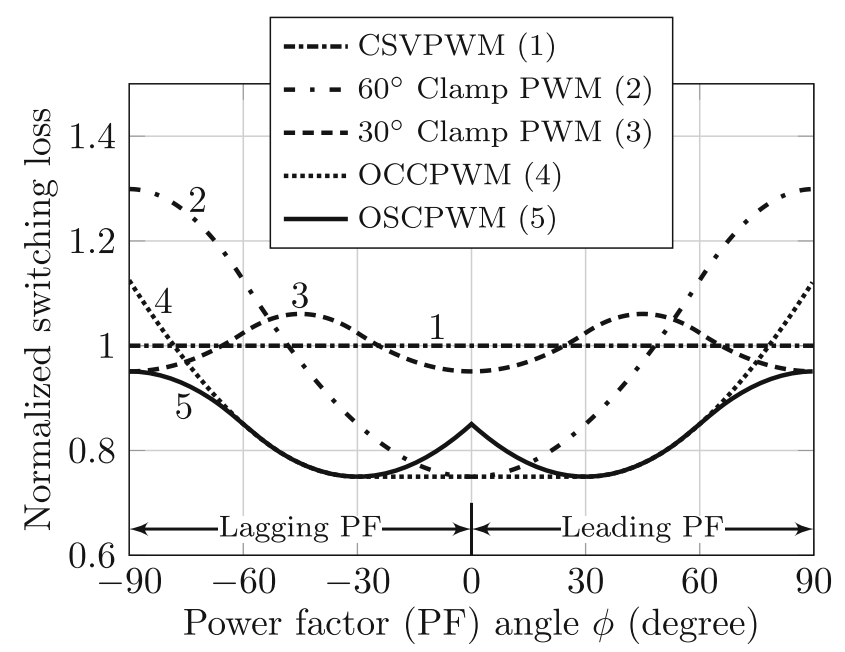

(b)

Figure 4. (a) Variation of $\gamma_{\text {opt }}$ against power factor angle for optimal continual clamp PWM (OCCPWM) and optimal splitclamp PWM (OSCPWM). (b) Normalized switching loss from different BCPWM methods; normalization is with respect to CSVPWM [17].

\section{Analytical evaluation of torque ripple and current ripple from CCPWM and SCPWM}

Closed-form expressions for harmonic distortion factor and torque ripple factor with CCPWM and SCPWM are derived analytically in this section.

\subsection{Analysis of current ripple over a sub-cycle}

For a voltage reference vector $\boldsymbol{V}_{\boldsymbol{r e f}}$ as shown in figure 5(a) (or an equivalent set of three-phase reference voltages), the applied voltage vector at any instant in the given sub-cycle is either $\boldsymbol{V}_{\mathbf{0}}, \boldsymbol{V}_{\mathbf{1}}$ or $\boldsymbol{V}_{\mathbf{2}}$. The corresponding error voltage vectors are $\boldsymbol{V}_{\text {err }, \mathbf{0}}, \boldsymbol{V}_{\boldsymbol{e r r}, \mathbf{1}}$ and $\boldsymbol{V}_{\boldsymbol{e r r}, \mathbf{2}}$, respectively, as shown in figure 5(a). In CCPWM or SCPWM, the given $\boldsymbol{V}_{\text {ref }}$ is realized using the switching sequence 7-2-1 (figure 5(b)) or sequence 0-1-2 (figure 5(c)). In both cases, the active vectors $V_{1}$ and $V_{2}$ are applied for durations $T_{1}$ and $T_{2}$, respectively, where

$$
\begin{gathered}
T_{1}=\frac{V_{r e f}}{V_{d c}} \frac{\sin \left(60^{\circ}-\alpha\right)}{\sin \left(60^{\circ}\right)} T_{s}, T_{2}=\frac{V_{r e f}}{V_{d c}} \frac{\sin (\alpha)}{\sin \left(60^{\circ}\right)} T_{s}, \\
T_{0}=T_{s}-\left(T_{1}+T_{2}\right) .
\end{gathered}
$$

The zero vector is applied for the remaining duration of $T_{0}$, defined in eq. (4b). Here, $V_{\text {ref }}$ and $\alpha$ are the magnitude and angle, respectively, of the reference vector $V_{r e f} ; V_{d c}$ is the dc bus voltage.

When this $\boldsymbol{V}_{\boldsymbol{r e f}}$ is realized using sequence 721 , the $q$-axis applied voltage $v_{q}$ and the $d$-axis applied voltage $v_{d}$ vary over the sub-cycle as shown in figure 5(b). The average value of $v_{q}$ over a sub-cycle equals $V_{\text {ref }}$ (i.e., the $q$-axis component of $\boldsymbol{V}_{\boldsymbol{r e f}}$ ), while the average value of $v_{d}$ is zero. The $q$-axis stator flux ripple $\psi_{q}$ and the $d$-axis stator flux ripple $\psi_{d}$ are time integrals of $\left(v_{q}-V_{\text {ref }}\right)$ and $v_{d}$, respectively. Variations of $\psi_{q}$ and $\psi_{d}$ over the sub-cycle for sequence 721 are also shown in figure 5(b). The voltages along $d$ - and $q$-axes and the corresponding flux ripple for sequence 012 are illustrated in figure 5(c).

From figures 5(b) and (c), the RMS value of $\psi_{d}$ (denoted by $F_{d, S E Q}$ ) and that of $\psi_{q}$ (denoted by $F_{q, S E Q}$ ) corresponding to a sequence $S E Q$ (where $S E Q=012$ or 721) can be expressed in terms of $T_{s}, V_{\text {ref }}$ and $\alpha$ as shown by equations (5a) and (5b), respectively:

$$
\begin{gathered}
F_{d, S E Q}=T_{s} \sqrt{A_{3 d} V_{r e f}^{3}} ; A_{3 d}=\frac{\sqrt{3}}{27}\left(6 a b^{2}-8 a^{2} b^{3}\right), \\
F_{q, S E Q}=T_{s} \sqrt{A_{2 q} V_{r e f}^{2}+A_{3 q} V_{r e f}^{3}+A_{4 q} V_{r e f}^{4}} .
\end{gathered}
$$

The coefficients $A_{2 q}, A_{3 q}$ and $A_{4 q}$ are tabulated in table 2. They are simplified versions of the coefficients reported in [22]. It can be observed that the RMS $d$-axis flux ripple $F_{d, S E Q}$ is the same for sequences 012 and 721 , since $A_{3 d}$ is the same.

The quantities $F_{d, S E Q}$ and $F_{q, S E Q}$ are used to evaluate the harmonic distortion and torque ripple from different PWM methods as discussed in the following sections.

\subsection{Analytically derived closed-form expressions for torque ripple factor}

Torque ripple factor $F_{T R F}$ is the RMS value of $q$-axis flux ripple over a sector, normalized with respect to the fundamental flux $\psi_{1}$ as shown [33]:

$$
F_{T R F}=\frac{1}{\psi_{1}} \sqrt{\frac{3}{\pi} \int_{0}^{\frac{\pi}{3}} F_{q, S E Q}^{2} d \alpha}, \quad \text { where } \psi_{1}=\frac{V_{r e f}}{\omega} .
$$




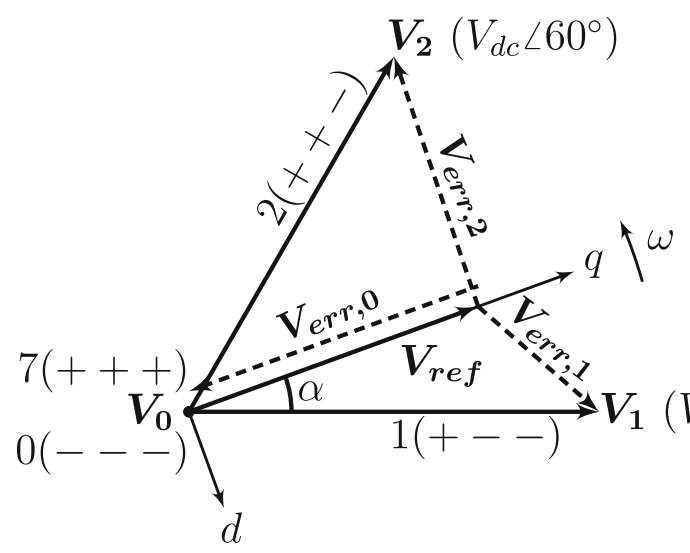

(a)

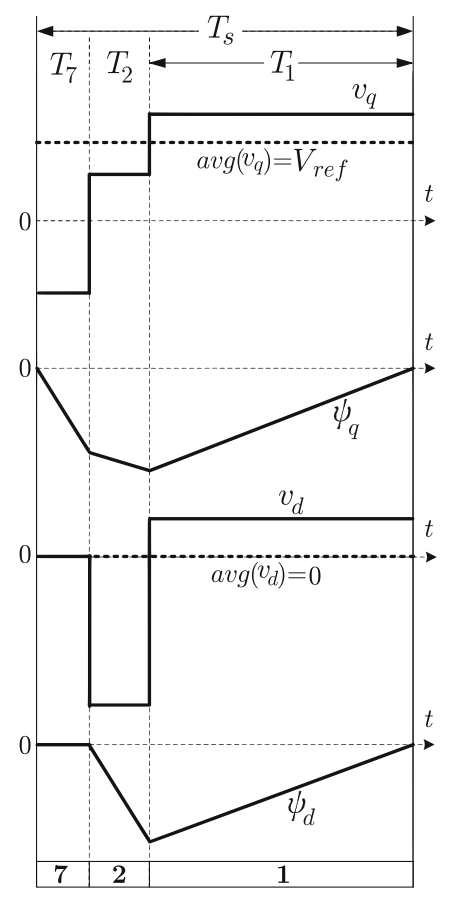

(b)

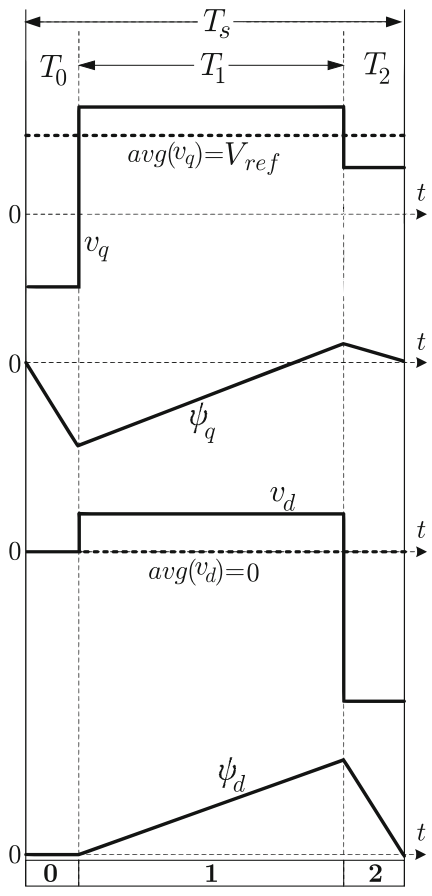

(c)

Figure 5. Stator flux ripple vector over a sub-cycle for $V_{\text {ref }}=0.8 V_{d c}$ and $\alpha=10^{\circ}$ for sequences 012 and 721 . (a) Error voltage vectors $\boldsymbol{V}_{\boldsymbol{e r r}, \mathbf{1}}, \boldsymbol{V}_{\boldsymbol{e r r}, \mathbf{2}}$ and $\boldsymbol{V}_{\boldsymbol{e r r}, \mathbf{0}},(\mathbf{b})$ orthogonal components of stator flux ripple vector over a sub-cycle for sequence 721 and (c) corresponding components for sequence 012 .

Table 2. Coefficients $A_{2 q}, A_{3 q}$ and $A_{4 q}$ for different sequences.

\begin{tabular}{lccc}
\hline SEQ & $A_{2 q}$ & $9 \sqrt{3} A_{3 q}$ & $36 A_{4 q}$ \\
\hline 0127 & $\frac{1}{12}$ & $-3 a-8 a b^{2}$ & $3-16 a b^{3}+12 b^{2}$ \\
& & $+2 a^{2} b+8 a^{2} b^{3}$ & \\
012 & $\frac{1}{3}$ & $-12 a-14 a b^{2}$ & $4-8 a b+32 a^{3} b$ \\
721 & $\frac{1}{3}$ & $-4 a^{2} b+8 a^{2} b^{3}+9 b$ & \\
& & $-12 a-2 a b^{2}$ & $4+8 a b-32 a^{2} b^{2}$ \\
$a=\sin \left(\frac{\pi}{3}+\alpha\right) ;$ & $b=\sin \left(\frac{\pi}{3}-\alpha\right)$
\end{tabular}

Here, $\psi_{1}$ is the magnitude of fundamental flux, $\omega=2 \pi f_{1}$ and $f_{1}$ is the fundamental frequency of stator voltages.

When different sequences are used over different subsectors in a sector, the integration in (6) needs to be carried out over the individual sub-sectors. In case of CCPWM, sequence 721 is used in the region $0^{\circ} \leq \alpha<\gamma$ and sequence 012 is employed in the region $\gamma \leq \alpha<60^{\circ}$ in a sector. Hence, the torque ripple factor for CCPWM, denoted by $F_{T R F, C C}$, is evaluated as follows:

$$
F_{T R F, C C}=\frac{1}{\psi_{1}} \sqrt{\frac{3}{\pi}\left[\int_{0}^{\gamma} F_{q, 721}^{2} d \alpha+\int_{\gamma}^{\frac{\pi}{3}} F_{q, 012}^{2} d \alpha\right]} .
$$

Similarly, the torque ripple factor for SCPWM $F_{T R F, S C}$ with arbitrary $\gamma$ is given by

$$
F_{T R F, S C}=\frac{1}{\psi_{1}} \sqrt{\frac{3}{\pi}\left[\int_{0}^{\gamma} F_{q, 012}^{2} d \alpha+\int_{\gamma}^{\frac{\pi}{3}} F_{q, 721}^{2} d \alpha\right]} .
$$

Evaluation of the above integrals in (7) and (8), followed by simplification, leads to the following closed-form analytically derived expression for $F_{T R F}$ for CCPWM and SCPWM with any general $\gamma$ :

$$
F_{T R F}=\omega T_{s} \sqrt{C_{0 q}+C_{1 q} V_{r e f}+C_{2 q} V_{r e f}^{2}}
$$

The coefficients $C_{0 q}, C_{1 q}$ and $C_{2 q}$ for CCPWM and SCPWM are tabulated in table 3 . While the coefficient $C_{0 q}$ is a constant, the coefficients $C_{1 q}$ and $C_{2 q}$ are trigonometric functions of angle $\gamma$. The corresponding coefficients for CSVPWM are also given for comparison.

\subsection{Analytically derived closed-form expressions for harmonic distortion factor}

The RMS value of $d$-axis flux ripple over a sector can be evaluated in a similar manner as that of $q$-axis flux ripple. The $d$-axis flux distortion factor $F_{D I S T \_d}$ is given by eq. (10):

$$
F_{D I S T \_d}=\frac{1}{\psi_{1}} \sqrt{\frac{3}{\pi} \int_{0}^{\frac{\pi}{3}} F_{d, S E Q}^{2} d \alpha .}
$$


Table 3. Coefficients $C_{0 q}, C_{1 q}$ and $C_{2 q}$ for different PWM methods.

\begin{tabular}{lccc}
\hline PWM & $C_{0 q}$ & $C_{1 q}$ & $C_{2 q}$ \\
\hline CCPWM & $\frac{1}{3}$ & $-\frac{44 \sqrt{3}}{135 \pi}-\frac{1}{3 \pi}(6 e-f)$ & $\frac{1}{3}+\frac{\sqrt{3}}{12 \pi}(2 g-h)$ \\
SCPWM & $\frac{1}{3}$ & $-\frac{314 \sqrt{3}}{135 \pi}+\frac{1}{3 \pi}(6 e-f)$ & $\frac{4 \pi+3 \sqrt{3}}{12 \pi}-\frac{\sqrt{3}}{12 \pi}(2 g-h)$ \\
$e=\sin \left(\gamma+\frac{\pi}{3}\right) ; f=\sin (3 \gamma) ; g=\sin \left(2 \gamma+\frac{\pi}{6}\right) ; h=\sin \left(4 \gamma-\frac{\pi}{6}\right)$ \\
CSVPWM & $\frac{1}{12}$ & $-\frac{44 \sqrt{3}}{135 \pi}$ & $\frac{4 \pi-3 \sqrt{3}}{24 \pi}$ \\
\hline
\end{tabular}

Since $F_{d, S E Q}$ is the same for sequences 012 and 721 as mentioned in the previous section, $F_{D I S T \_d}$ is independent of $\gamma$ for both CCPWM and SCPWM. $F_{D I S T \_} d$ and $F_{T R F}$ are squared and added to result in the square of the harmonic distortion factor $F_{D I S T}$, defined in (11):

$$
\begin{gathered}
F_{D I S T}=\sqrt{F_{T R F}^{2}+F_{D I S T \_d}^{2}} \\
=\omega T_{s} \sqrt{C_{0 q}+\left(C_{1 q}+C_{1 d}\right) V_{r e f}+C_{2 q} V_{r e f}^{2}}, \\
C_{1 d}=\frac{4 \sqrt{3}}{135 \pi} .
\end{gathered}
$$

$F_{D I S T}$ for specific PWM techniques are functions of $V_{\text {ref }}$, $\omega$ and $T_{s}[16,21,33]$. Here $F_{D I S T}$ and $F_{T R F}$ have been derived for two classes of PWM techniques, namely, CCPWM with any general $\gamma$, and SCPWM with any general $\gamma$. Therefore, both $F_{D I S T}$ and $F_{T R F}$, pertaining to these two classes of PWM methods, are functions of $V_{\text {ref }}, \omega, T_{s}$ and $\gamma$.

\subsection{Performance of CCPWM and SCPWM}

The first derivatives of the analytically derived expressions of $F_{T R F}$ for CCPWM and SCPWM are shown plotted against $\gamma$ for different values of $V_{\text {ref }}$ in figure 6(a). As seen, $\gamma=0^{\circ}$ and $\gamma=60^{\circ}$ are the minima of $F_{T R F}$ for CCPWM, since the first derivative $\frac{d}{d \gamma} F_{T R F}$ is zero and the second derivative is positive.

In case of SCPWM, $\gamma=0^{\circ}$ and $\gamma=60^{\circ}$ are the points of maxima for $F_{T R F}$, as $\frac{d}{d \gamma} F_{T R F}=0$ and the slope of $\frac{d}{d \gamma} F_{T R F}$ is negative.

Further, $F_{T R F}$ are equal for both CCPWM and SCPWM at $\gamma=0^{\circ}$ as well as $\gamma=60^{\circ}$. This can be seen from the expressions for the coefficients $C_{1 q}$ and $C_{2 q}$ in table 3 . This is true for $F_{D I S T}$ as well.

Moreover, one can see that $\gamma=30^{\circ}$ is the maximum for $F_{T R F}$ with CCPWM, while $\gamma=30^{\circ}$ is the minimum for $F_{T R F}$ with SCPWM. This is demonstrated for $V_{r e f}=$ $0.866 V_{d c}$ in figure $6(\mathrm{~b})$. This holds good for $F_{D I S T}$ also.

Thus, CCPWM with $\gamma=30^{\circ}$ (or $60^{\circ}$ clamp PWM) is the worst among CCPWM methods in terms of $F_{D I S T}$ and $F_{T R F}$. On the other hand, SCPWM with $\gamma=30^{\circ}$ (or $30^{\circ}$ clamp PWM) is the best among SCPWM methods in these respects. Also, for any $\gamma$ in the range $0^{\circ}<\gamma<60^{\circ}$, SCPWM

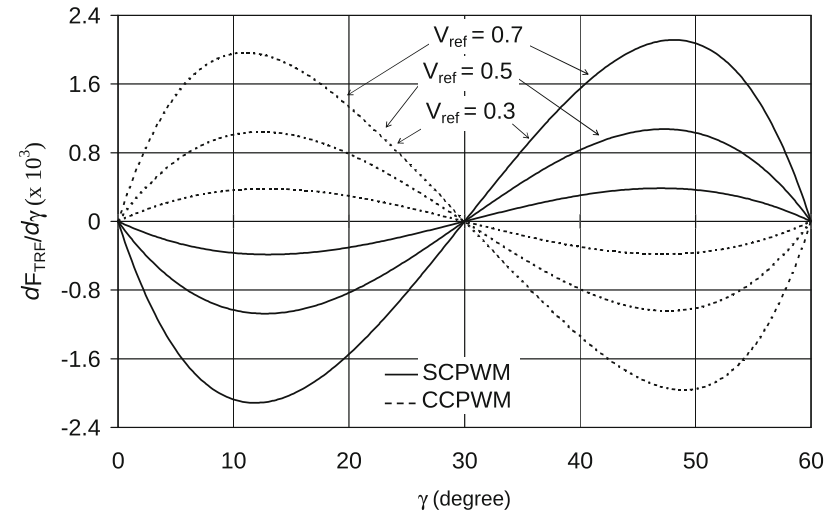

(a)

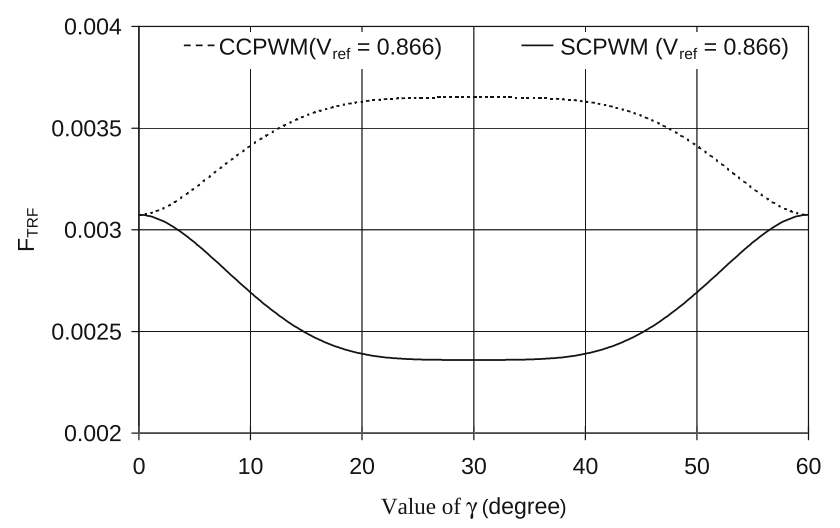

(b)

Figure 6. Variation of (a) $\frac{d}{d \gamma} F_{T R F}$ and (b) $F_{T R F}$ with the angle $\gamma$.

is better than CCPWM. Figure 7(a) shows the superiority of SCPWM over CCPWM in terms of $F_{T R F}$ at any $V_{\text {ref }}$. Similarly, figure 7(b) demonstrates the superior performance of SCPWM in terms of $F_{D I S T}$ over CCPWM at any $V_{\text {ref }}$.

The best reduction in harmonic distortion and that in torque ripple are achieved with SCPWM when $\gamma=30^{\circ}$. Hence, SCPWM with $\gamma=30^{\circ}$ (or the $30^{\circ}$ clamp PWM) is the optimal BCPWM method in terms of torque ripple and current ripple. However, this method is not the best in terms of inverter switching loss as discussed in the previous section. Optimal CCPWM (OCCPWM) and optimal SCPWM (OSCPWM) are designed to minimize the switching loss. THD and torque ripple with these methods are evaluated in the following section.

\section{Performance of optimal CCPWM and optimal SCPWM}

At any given $V_{r e f}$, the PWM waveform changes with power factor in case of optimal CCPWM (OCCPWM) and optimal SCPWM (OSCPWM) schemes. Hence $F_{T R F}$ and $F_{D I S T}$ vary 


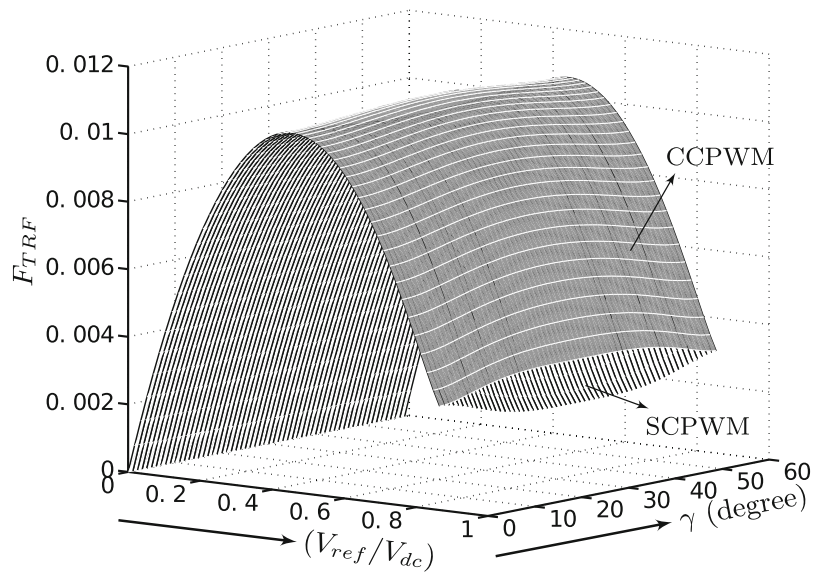

(a)

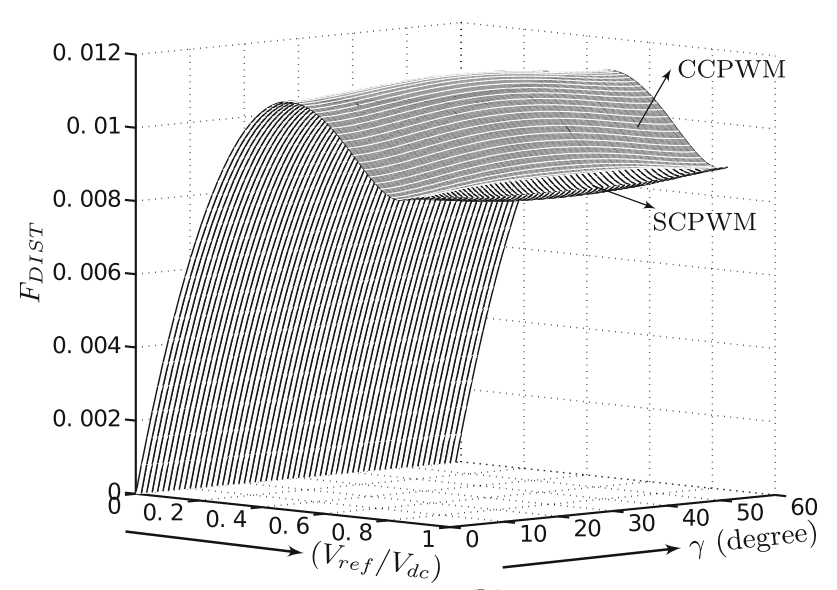

(b)

Figure 7. (a) Torque ripple factor $F_{T R F}$ and (b) harmonic distortion factor $F_{D I S T}$ of CCPWM and SCPWM in the whole range of $V_{r e f}$ and $\gamma$. Average switching frequency is $1.5 \mathrm{kHz}$ in both the cases.

with power factor as shown in figure 8(a) and figure 8(b), respectively, at $V_{\text {ref }}=0.866 V_{d c}$ for the two optimal PWM techniques. Here, the values of $F_{T R F}$ and $F_{D I S T}$ from different PWM methods are normalized with respect to those from CSVPWM.

As seen from the figure, CCPWM with $\gamma=30^{\circ}$ (i.e., $60^{\circ}$ clamp PWM) leads to the highest torque ripple at this $V_{r e f}$ (roughly 10\% higher than that from CSVPWM). Optimal positioning of the $60^{\circ}$-clamping interval (i.e., OCCPWM) not only reduces the switching loss, compared with $60^{\circ}$ clamp PWM, as shown in figure 4(b), but also improves the torque pulsations at low and medium power factors as shown in figure $8(a)$.

Optimal splitting of the clamping interval (i.e., OSCPWM) leads to superior performance than OCCPWM in terms of torque ripple as shown in figure 8(a). The $30^{\circ}$ clamp PWM (or equal splitting of the clamping interval) leads to the lowest pulsating torque, which is roughly $30 \%$ lower than that of CSVPWM.

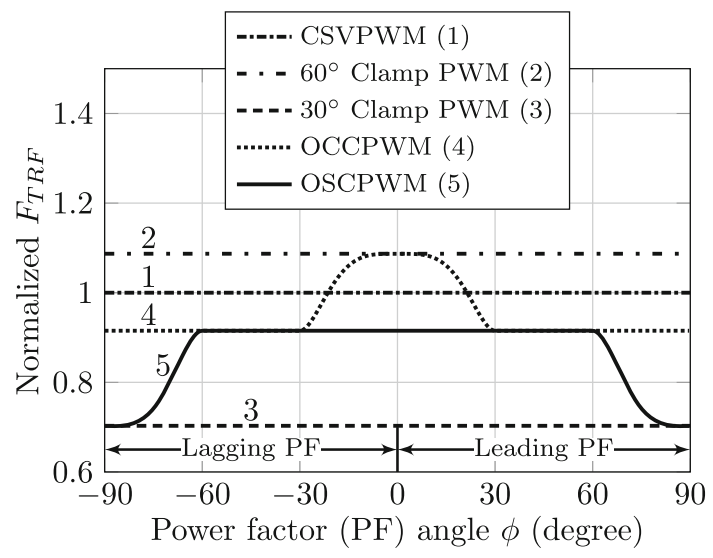

(a)

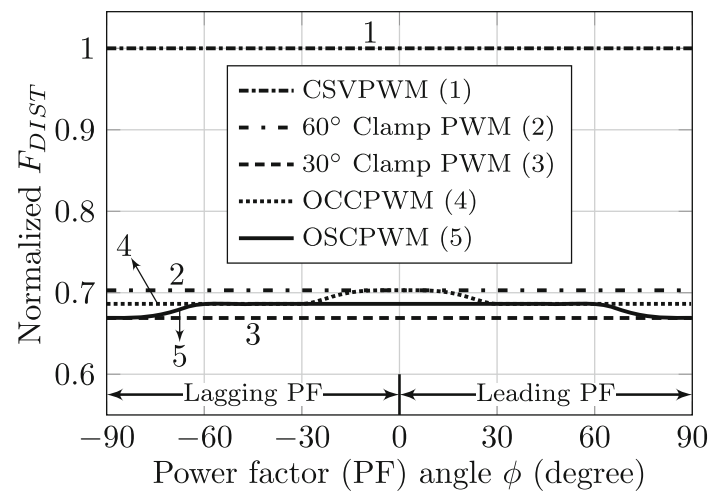

(b)

Figure 8. Variation of (a) normalized $F_{T R F}$ and (b) normalized $F_{D I S T}$ against power factor angle from different PWM methods. Normalization is with respect to CSVPWM. $V_{r e f}=0.866 V_{d c}$ in both the cases.

Exclusively from a torque ripple perspective, $30^{\circ}$ clamp PWM would be the best at high modulation indices. However, OSCPWM reduces the switching loss significantly, compared with both CSVPWM and $30^{\circ}$ clamp PWM, at any power factor. Hence, OSCPWM would be a good choice from the considerations of both switching loss and pulsating torque.

The normalized $F_{T R F}$ pertaining to OSCPWM is lower than 1, (i.e., better than that of CSVPWM) for any $V_{r e f}>0.8 V_{d c}$ at any power factor, as shown in figure 9(a). OSCPWM is always better than OCCPWM as shown in the figure, except in the regions marked A and B in the figure, where the $F_{T R F}$ pertaining to the two methods are equal.

In terms of the THD, any BCPWM method is much better than CSVPWM at $V_{r e f}=0.866 V_{d c}$ as seen in figure 8(b). In fact, for any $V_{r e f}>0.65 V_{d c}$, OSCPWM is superior to CSVPWM in terms of THD as shown in figure 9(b). The performance of OSCPWM is either better than or the same as that of OCCPWM under any operating condition. The $30^{\circ}$ clamp PWM is always the best method among BCPWM methods in terms of $F_{D I S T}$. OSCPWM is 


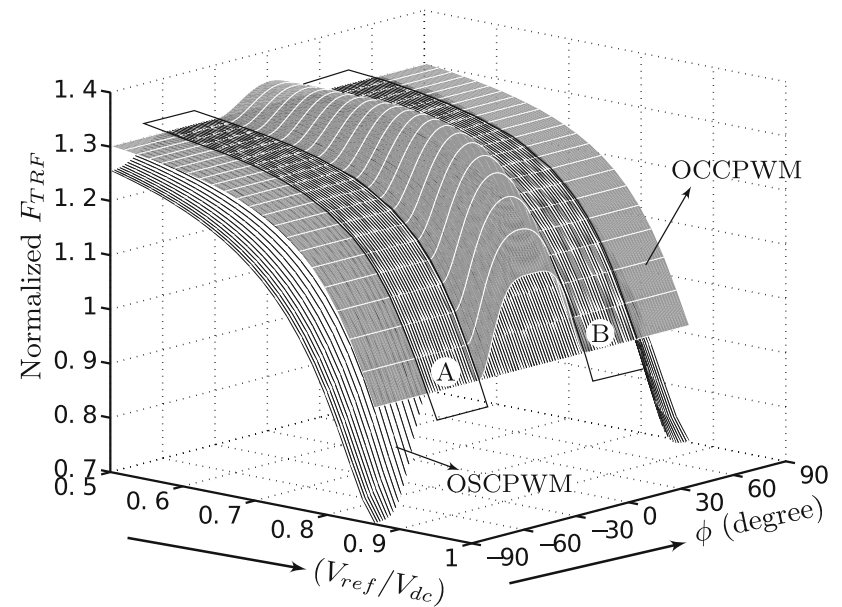

(a)

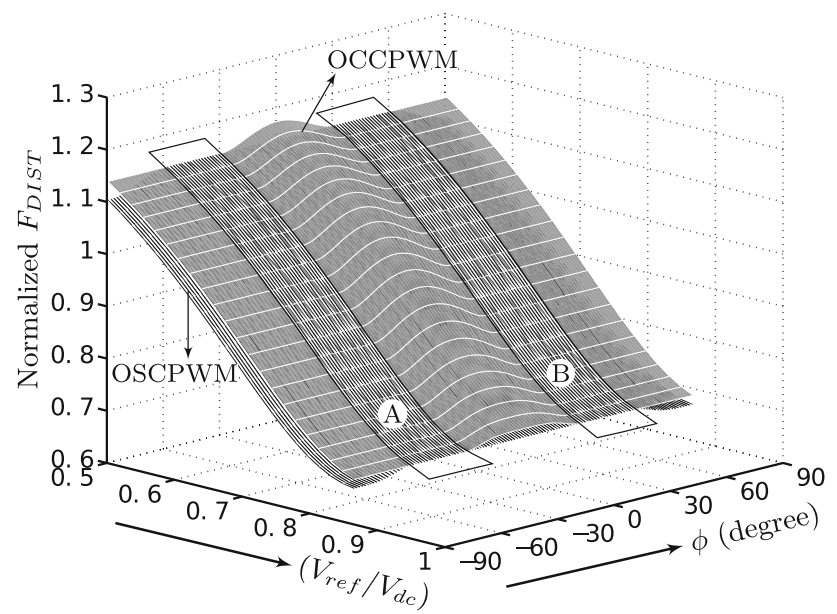

(b)

Figure 9. (a) Normalized $F_{T R F}$ and (b) normalized $F_{D I S T}$ of OCCPWM and OSCPWM in the range $0.5 V_{d c}<V_{\text {ref }}<0.866 V_{d c}$ and $0^{\circ}<\gamma<60^{\circ}$. Normalization is with respect to the corresponding values of CSVPWM.

very close to $30^{\circ}$ clamp PWM in terms of THD, and is better than $30^{\circ}$ clamp PWM in terms of switching loss at any power factor.

The machine-independent analytically derived expressions for line current distortion and torque ripple, derived in section 3 , are validated experimentally in the following sections.

\section{Experimental study on waveform quality}

The experimental set-up consists of a 10-kVA two-level IGBT-based inverter, feeding a $2.2-\mathrm{kW}, 415-\mathrm{V}, 50-\mathrm{Hz}$ deltaconnected squirrel-cage induction motor. A TMS320LF2407A-based digital platform is used to implement the generalized CCPWM and SCPWM schemes. The voltage to frequency ratio is kept constant at its rated value.
The dc bus voltage is maintained at $600 \mathrm{~V}$; the carrier frequency $\left(f_{c}\right)$ and the average switching frequency $[17,22]$ of the inverter $\left(f_{s w}=\frac{2}{3} f_{c}\right)$ are 2.25 and $1.5 \mathrm{kHz}$, respectively.

\subsection{Quality of voltage waveform}

Figures 10(a) and (b) show the measured harmonic spectra of line voltage at a fundamental frequency of $45 \mathrm{~Hz}$ corresponding to CCPWM $\left(\gamma=30^{\circ}\right)$ and $\operatorname{SCPWM}\left(\gamma=30^{\circ}\right)$ schemes, respectively. In both the cases, the dominant components are found to be around $n f_{c}$, where $f_{c}$ is carrier frequency and $n=1,2,3 \ldots$

As seen, the dominant components in the first side-band around $f_{c}$ are closer to $f_{c}$ for CCPWM and are farther from $f_{c}$ for SCPWM. More importantly, there is a visible reduction in the first side-band harmonics with SCPWM; the dominant harmonic is reduced from around $120 \mathrm{~V}$ (RMS) with CCPWM to about $95 \mathrm{~V}$ (RMS) with SCPWM. Hence, the SCPWM scheme is found to be better in terms of weighted THD of line voltage $\left(V_{W T H D}\right)$ than CCPWM scheme as indicated in figure 10. $V_{W T H D}$ is defined as

$$
V_{W T H D}=\frac{1}{V_{1}} \sqrt{\sum_{n \neq 1}\left(V_{n} / n\right)^{2}}
$$

where $V_{1}$ and $V_{n}$ are the RMS values of fundamental and $n^{\text {th }}$ harmonic components, respectively, of the line voltage.

The harmonic spectrum of line voltage is measured at every $5 \mathrm{~Hz}$, between 30 and $50 \mathrm{~Hz}$ for a few SCPWM and CCPWM schemes with $\gamma=0^{\circ}, 15^{\circ}, 30^{\circ}, 45^{\circ}$ and $60^{\circ}$. Figures 11(a) and (b) show the measured $V_{W T H D}$ corresponding to CCPWM and SCPWM schemes for these values of $\gamma$. In conformity to previous findings, $30^{\circ}$ clamp PWM results in a lower distortion than $60^{\circ}$ clamp PWM as seen in figure 11(a). SCPWM with $\gamma=15^{\circ}$ and $45^{\circ}$ are better than CCPWM with $\gamma=15^{\circ}$ and $45^{\circ}$ as evidenced by the results in figure 11(b). These experimental results support the analytical finding that SCPWM is better than CCPWM in terms of harmonic distortion for any $0^{\circ}<\gamma<60^{\circ}$ at any modulation index.

\subsection{Quality of current waveform}

Figures 12(a) and (b) show the line current waveforms at a fundamental frequency of $45 \mathrm{~Hz}$ corresponding to CCPWM $\left(\gamma=30^{\circ}\right)$ and $\operatorname{SCPWM}\left(\gamma=30^{\circ}\right)$, respectively. It can be seen that the worst-case peak-to-peak ripple in current with SCPWM is less than that with CCPWM. The peak-to-peak ripple with SCPWM is less than that with CCPWM in the regions marked ' $\mathrm{x}$ ' and ' $\mathrm{z}$ ', while it is more than that with CCPWM in the region ' $y$ ' as shown in figure 12. However, the intervals ' $x$ ' and ' $z$ ' add up to being much longer than the interval ' $y$ '. Hence SCPWM results in lower value of THD in line current than CCPWM as indicated in figure 12. THD in line current $I_{T H D}$ is defined as 


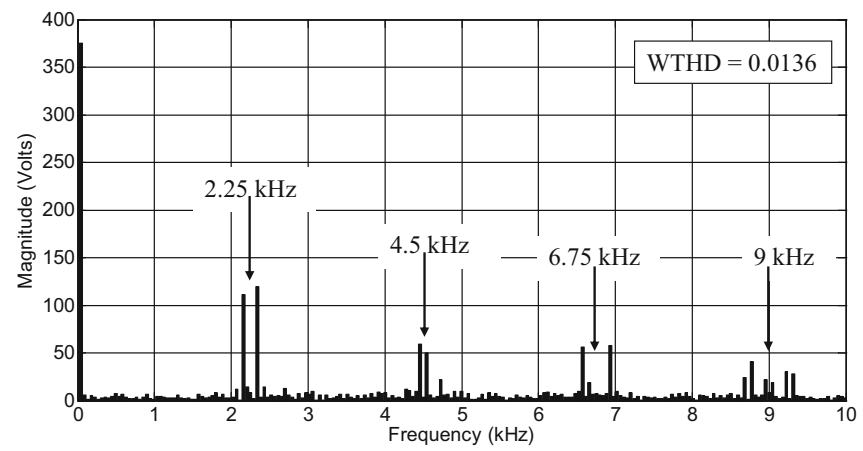

(a)

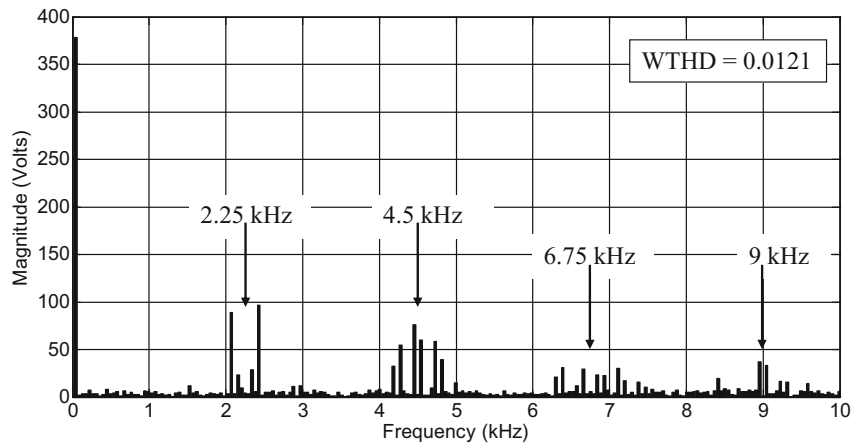

(b)

Figure 10. Measured harmonic spectra of line voltages at $V_{d c}=600 \mathrm{~V}, f_{1}=45 \mathrm{~Hz}$ and $f_{s w}=1.5 \mathrm{kHz}$ corresponding to (a) CCPWM $\left(\gamma=30^{\circ}\right)$ and $(\mathbf{b}) \operatorname{SCPWM}\left(\gamma=30^{\circ}\right)$.

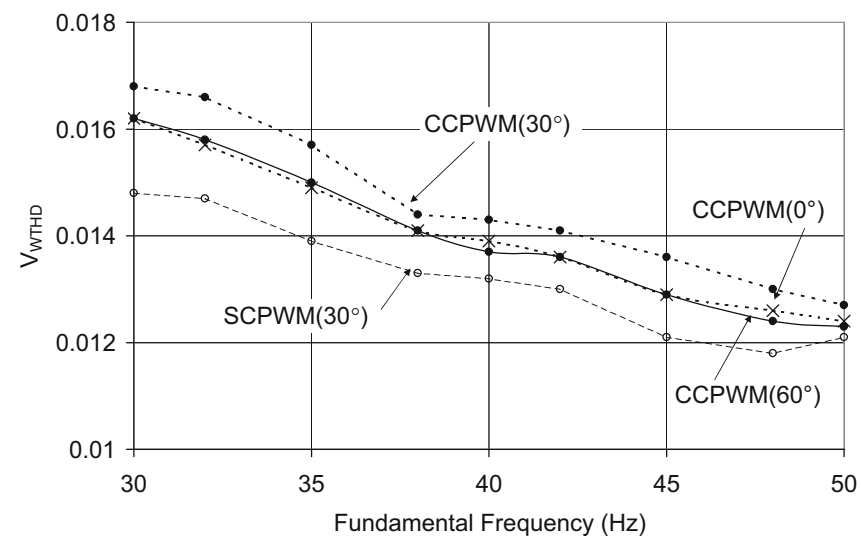

(a)

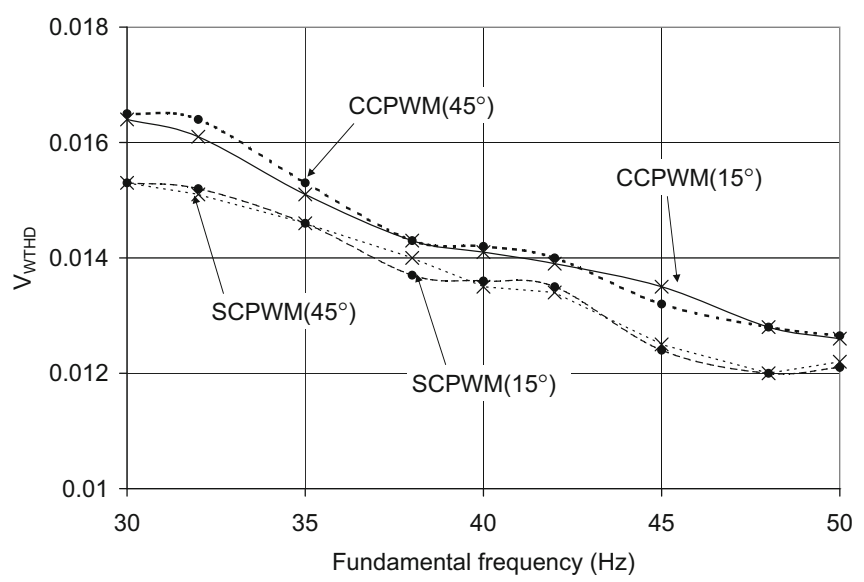

(b)

Figure 11. Measured $V_{W T H D}$ at $V_{d c}=600 \mathrm{~V}$ and $f_{s w}=1.5 \mathrm{kHz}$ corresponding to various CCPWM and SCPWM schemes: (a) $\gamma=$ $0^{\circ}, 30^{\circ}, 60^{\circ}$ and $(\mathbf{b}) \gamma=15^{\circ}, 45^{\circ}$.

$$
I_{T H D}=\frac{1}{I_{1}} \sqrt{\sum_{n \neq 1} I_{n}^{2}}
$$

where $I_{1}$ and $I_{n}$ are the RMS values of fundamental and $n^{\text {th }}$ harmonic components, respectively, of the line current.

The line current spectra, corresponding to CCPWM and SCPWM schemes with $\gamma=0^{\circ}, 15^{\circ}, 30^{\circ}, 45^{\circ}$ and $60^{\circ}$, are measured over the fundamental frequency range of 30 $50 \mathrm{~Hz}$ in steps of $5 \mathrm{~Hz}$. The experimental values of $I_{T H D}$ therefrom are shown plotted in figures 13(a) and (b). Once again, the experimental results confirm the superiority of SCPWM over CCPWM for any $\gamma$ in the range $0^{\circ}<\gamma<60^{\circ}$.

\section{Analytical, simulation and experimental study on pulsating torque}

Figures 14 and 15 present the torque ripple waveforms over a sector with CCPWM, $\gamma=30^{\circ}$ (i.e., $60^{\circ}$ clamp PWM) and SCPWM, $\gamma=30^{\circ}$ (i.e., $30^{\circ}$ clamp PWM), respectively, on a 400-V, 5-hp, 3-phase, 4-pole, 50-Hz, squirrel-cage induction motor drive, at a fundamental frequency of $48 \mathrm{~Hz}$. The average switching frequency is $1 \mathrm{kHz}$ for both the methods.

The ripple in the developed torque $\widetilde{m}_{d}$ is first evaluated analytically for both techniques using the following equations [20]:

$$
\begin{gathered}
\widetilde{m}_{d}=K_{m d} \psi_{q} \\
K_{m d}=\frac{2}{3} \frac{P}{2} \frac{V_{R E F}}{\omega_{1}} \frac{1}{L_{o}}\left[\frac{1}{\left(\sigma_{s}+\sigma_{r}\right)}-1\right]
\end{gathered}
$$

where $\psi_{q}$ is the $q$-axis stator flux ripple, $K_{m d}$ is the torque constant and $L_{o}$ is the per-phase mutual inductance between stator and rotor; $\sigma_{s}$ and $\sigma_{r}$ are the stator and rotor leakage coefficients, respectively. Parameters of the 5-hp induction motor are $L_{o}=227 \mathrm{mH}, \sigma_{s}=\sigma_{r}=0.042$ and $K_{m d}=$ $100.68 \mathrm{~N}-\mathrm{m} / \mathrm{V}$-s.

Figures 14(a) and 15(a) show the analytically evaluated torque ripple waveforms over a sector with CCPWM and 


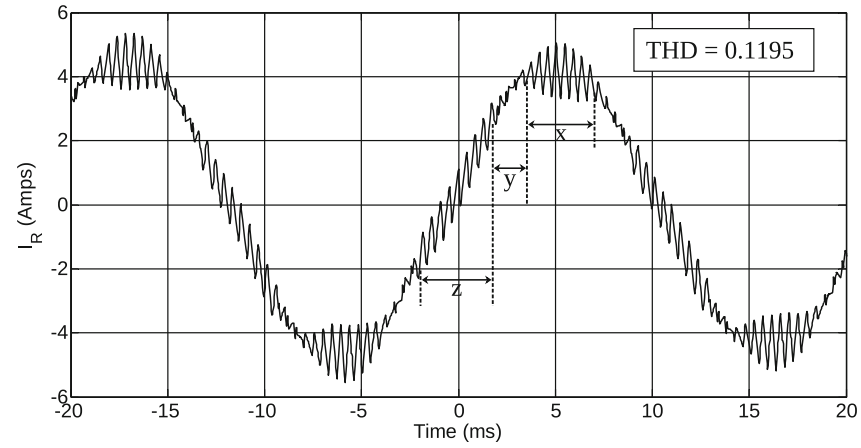

(a)

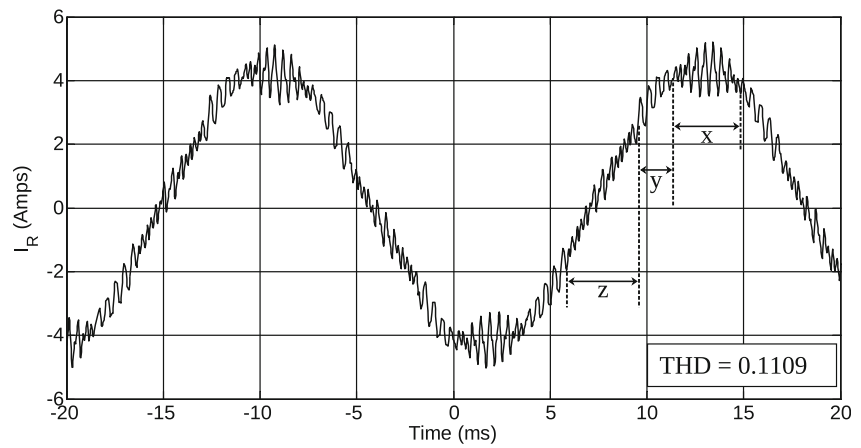

(b)

Figure 12. Measured current waveforms at $V_{d c}=600 \mathrm{~V}, f_{1}=45 \mathrm{~Hz}$ and $f_{s w}=1.5 \mathrm{kHz}$ corresponding to $(\mathbf{a}) \operatorname{CCPWM}\left(\gamma=30^{\circ}\right)$ and (b) $\operatorname{SCPWM}\left(\gamma=30^{\circ}\right)$.

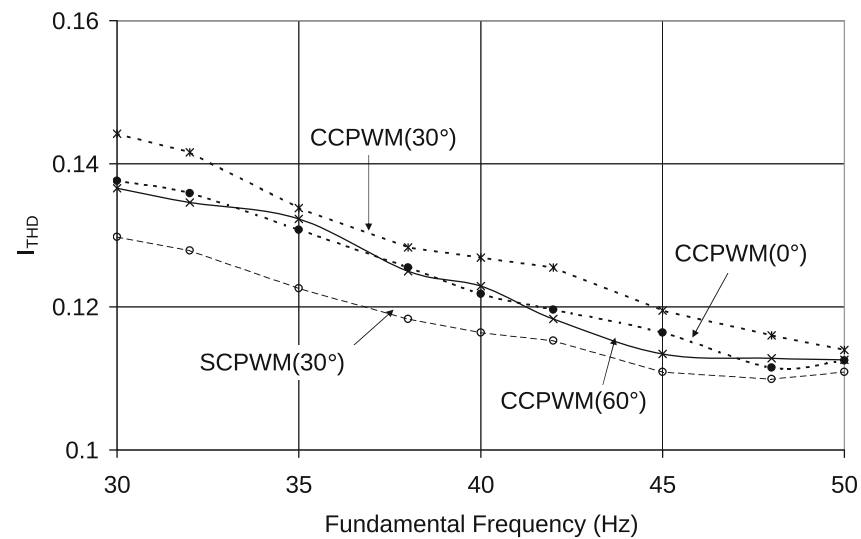

(a)

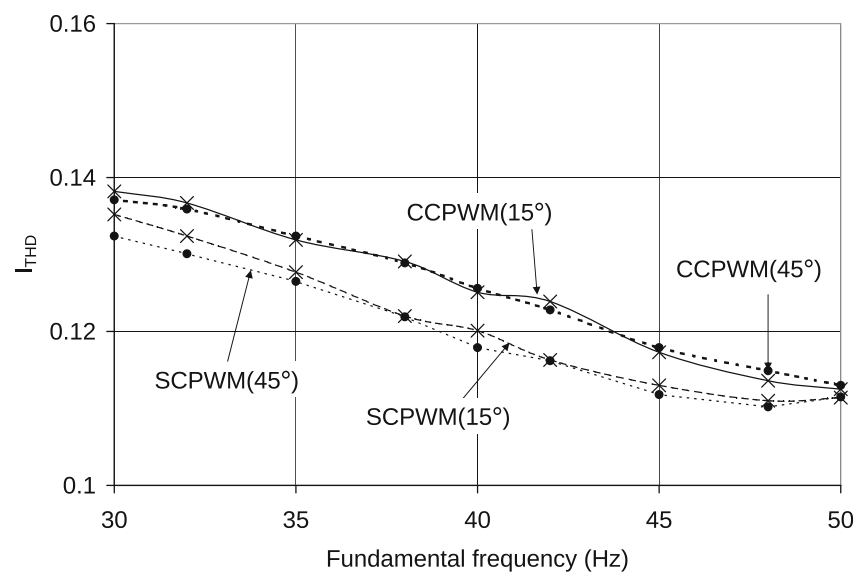

(b)

Figure 13. Measured $I_{T H D}$ at $V_{d c}=600 \mathrm{~V}$ and $f_{s w}=1.5 \mathrm{kHz}$ corresponding to various CCPWM and SCPWM schemes: (a) $\gamma=$ $0^{\circ}, 30^{\circ}, 60^{\circ}$ and $(\mathbf{b}) \gamma=15^{\circ}, 45^{\circ}$.

SCPWM, respectively, using (14). It can be observed that the peak-to-peak torque ripple with SCPWM is less than that with CCPWM.

The torque ripple waveforms are then obtained by numerical simulation using a standard dynamic model of induction motor [34], which is more detailed than the analytical model for torque ripple in (14). The numerical simulations are carried out using $\mathrm{C}$ and Python programming languages [35]. The simulated torque ripple waveforms with CCPWM, $\gamma=30^{\circ}$ and SCPWM, $\gamma=30^{\circ}$ are presented in figures 14(b) and 15(b), respectively. They confirm the analytical results in figures 14(a) and 15(a).

Figures 14(c) and 15(c) show the experimentally obtained torque ripple waveforms with CCPWM, $\gamma=30^{\circ}$ and SCPWM, $\gamma=30^{\circ}$, respectively. The 5-hp induction motor is fed from a 10-kVA IGBT-based two-level VSI, and the PWM methods are implemented on an ALTERA CycloneII field programmable gate array (FPGA)-based digital controller [36]. These torque ripple waveforms are obtained by feeding the measured voltages and currents to a standard machine model [37], implemented on the same
FPGA controller mentioned earlier. The experimental results in figures $14(\mathrm{c})$ and 15 (c) confirm the reduction in peak-to-peak torque ripple with SCPWM over CCPWM.

For completeness, the RMS torque ripple with CCPWM, $\gamma=30^{\circ}$ (i.e., $60^{\circ}$ clamp PWM), SCPWM, $\gamma=30^{\circ}$ (i.e., $30^{\circ}$ clamp PWM) and CSVPWM are measured over the fundamental frequency range of $30-50 \mathrm{~Hz}$. The values of measured RMS torque ripple from the three PWM methods are shown plotted against the fundamental frequency in figure 16. It can be seen that SCPWM is better than CCPWM in terms of torque ripple at any given speed of the drive. Further, SCPWM results in a lower torque pulsation than CSVPWM close to the rated speed.

\section{Conclusions}

Closed-form expressions for harmonic distortion factor and torque ripple factor are derived analytically for continual CCPWM scheme with any arbitrary position of clamping interval and for SCPWM scheme with any arbitrary 


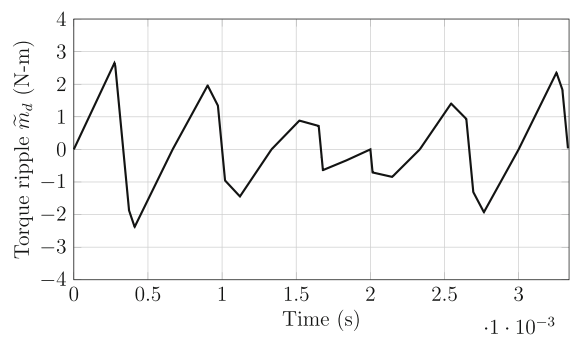

(a)

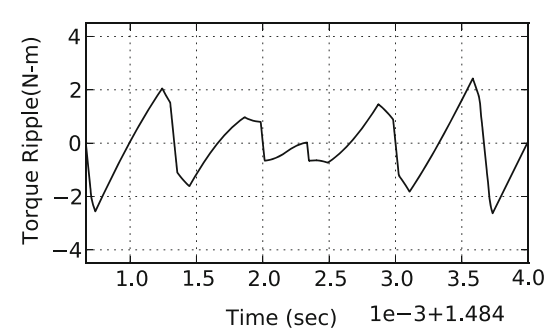

(b)

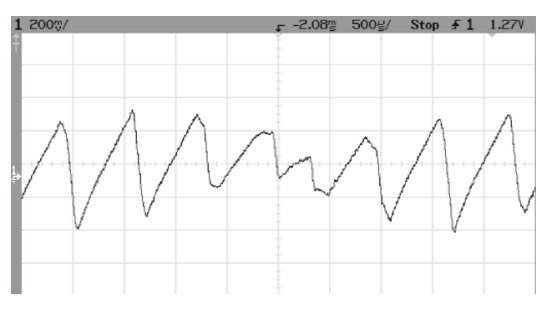

(c)

Figure 14. (a) Analytically evaluated instantaneous torque ripple, (b) simulated torque ripple and (c) experimentally obtained torque ripple from a 5-hp induction motor drive (xscale $=500 \mu \mathrm{s} /$ div, yscale $=1.53 \mathrm{~N}$-m/div) with $60^{\circ}$ clamp PWM at $f_{1}=48 \mathrm{~Hz}, V_{R E F}=$ $0.831 V_{d c}$ and $f_{s w}=1 \mathrm{kHz}$.

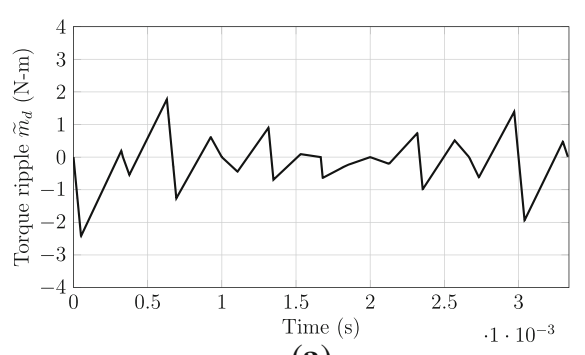

(a)

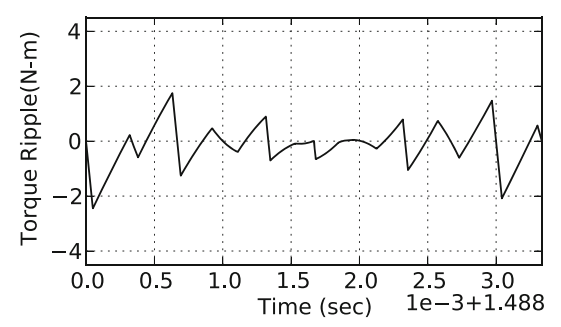

(b)

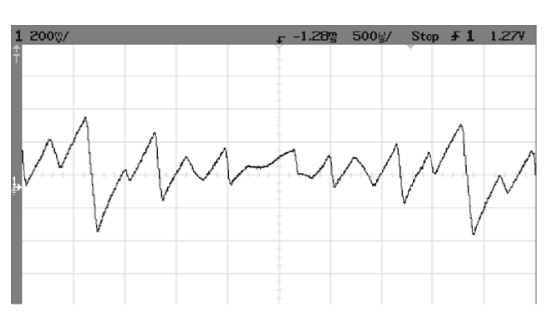

(c)

Figure 15. (a) Analytically evaluated instantaneous torque ripple, (b) simulated torque ripple and (c) experimentally obtained torque ripple from a 5 -hp induction motor drive (xscale $=500 \mu \mathrm{s} / \mathrm{div}$, yscale $=1.53 \mathrm{~N}-\mathrm{m} / \mathrm{div}$ ) with $30^{\circ} \mathrm{clamp} \mathrm{PWM}$ at $f_{1}=48 \mathrm{~Hz}, V_{R E F}=$ $0.831 V_{d c}$ and $f_{s w}=1 \mathrm{kHz}$.

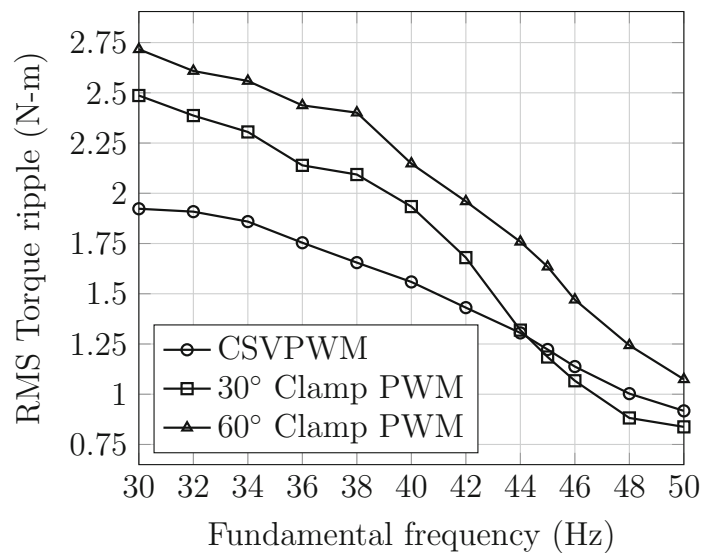

Figure 16. Experimental result: RMS torque ripple against fundamental frequency with different PWM techniques at an average switching frequency of $1 \mathrm{kHz}$.

splitting of the clamping interval. Analytical and experimental results demonstrate that splitting the $60^{\circ}$-clamping interval, either equally or unequally, is always superior in terms of line current distortion and torque ripple to clamping the phase continually for $60^{\circ}$ duration, regardless of the position of the clamping interval. Optimal positioning of clamping interval in CCPWM (referred to as OCCPWM) not only reduces the switching loss compared with CCPWM but also results in a lower pulsating torque and THD in line current. OCCPWM is outperformed by optimal split-clamp PWM (OSCPWM) in terms of both THD and torque ripple.

\section{References}

[1] Handley P G and Boys J T 1992 Practical real-time PWM modulators: an assessment. IEE Proc. B 139(2): 96-102

[2] Depenbrock M 1977 Pulse width control of a 3-phase inverter with nonsinusoidal phase voltages. In: IEEE International Semiconductor Power Converter Conference Record, pp. 399-403

[3] Madhu M and De G 1987 Novel control strategy for sinusoidal PWM inverters. IEEE Trans. Ind. Appl. IA-23(3): 561-566

[4] Katsunori T, Yasumasa O and Hisaichi I 1988 PWM technique for power MOSFET inverter. IEEE Trans. Power Electron. 3(3): 328-334

[5] van der Broeck H W 1991 Analysis of the harmonics in voltage fed inverter drives caused by PWM schemes with discontinuous switching operation. In: Proceedings of the EPE 91 Conference, Firenze, Italy, pp. 261-266

[6] Kolar J W, Ertl H and Franz C Z 1991 Influence of the modulation method on the conduction and switching losses of a PWM converter system. IEEE Trans. Ind. Appl. 21(6): 1063-1075

[7] Holmes D G 1996 The significance of zero space vector placement for carrier-based PWM schemes. IEEE Trans. Ind. Appl. 32(5): 1122-1129 
[8] Fukuda S and Suzuki K 1997 Harmonic evaluation of carrierbased PWM methods using harmonic distortion determining factor. In: Proceedings of IEEE PCC-1997, Nagaoka, Japan, pp. 259-264

[9] Halasz S and Zacharov A 1998 Voltage spectra of two-phase PWM techniques in inverter fed ac drives. In: Proceedings of the IEEE International Symposium on Industrial Electronics, Pretoria, South Africa, pp. 202-207

[10] Hava A M, Kerman R J and Lipo T A 1998 A high performance generalized discontinuous PWM algorithm. IEEE Trans. Ind. Appl. 34(5): 1059-1071

[11] Hava A M, Kerman R J and Lipo T A 1999 Simple analytical and graphical method for carrier based PWM-VSI drives. IEEE Trans. Power Electron. 14(1): 49-61

[12] Narayanan G and Ranganathan V T 2002 Two novel synchronized bus-clamping PWM strategies based on space vector approach for high power drives. IEEE Trans. Power Electron. 17(1): 84-93

[13] Narayanan G and Ranganathan V T 2002 Extension of operation of space vector PWM strategies with low switching frequencies using different over-modulation algorithms. IEEE Trans. Power Electron. 17(5): 788-798

[14] Holmes D G and Lipo T A 2003 Pulse width modulation for power converters - principles and practice. Piscataway, NJ: IEEE Press

[15] Zhao D, Narayanan G and Ayyanar R 2004 Switching loss characteristics of sequences involving active state division in space vector based PWM. In: Proceedings of IEEE-APEC04, pp. $479-485$

[16] Narayanan G and Ranganathan V T 2005 Analytical evaluation of harmonic distortion in PWM ac drives using the notion of stator flux ripple. IEEE Trans. Power Electron. 20(2): 466-474

[17] Narayanan G, Krishnamurthy H K, Zhao D and Ayyanar R 2006 Advanced bus-clamping PWM techniques based on space vector approach. IEEE Trans. Power Electron. 21(4): 974-984

[18] Asiminoaei L, Rodrguez P and Blaabjerg F Application of discontinuous PWM modulation in active power filters. IEEE Trans. Power Electron. 23(4): 1692-2006

[19] Narayanan G, Zhao D, Krishnamurthy H K, Ayyanar R, and Ranganathan V T 2008 Space vector based hybrid PWM techniques for reduced current ripple. IEEE Trans. Ind. Electron. 55(4): 1614-1627

[20] Basu K, Prasad J S S and Narayanan G 2009 Minimization of torque ripple in PWM AC drives. IEEE Trans. Ind. Electron. 56(2): 553-558

[21] Bhavsar T and Narayanan G 2009 Harmonic analysis of advanced bus-clamping PWM techniques. IEEE Trans. Power Electron. 24(10): 2347-2352

[22] Zhao D, Hari V S S P K, Narayanan G and Ayyanar R 2010 Space-vector-based hybrid pulsewidth modulation techniques for reduced harmonic distortion and switching loss. IEEE Trans. Power Electron. 25(3): 760-774

[23] Wu Y, Shafi M A, Knight A M and McMahon R A 2011 Comparison of the effects of continuous and discontinuous PWM schemes on power losses of voltage-sourced inverters for induction motor drives. IEEE Trans. Power Electron. 26(1): 182-191

[24] Nguyen T G, Hobraiche J, Patin N, Friedrich G and Vilain J P 2011 A direct digital technique implementation of general discontinuous pulse width modulation strategy. IEEE Trans. Ind. Electron. 58(9): 4445-4454

[25] Zhang D, Wang F, Burgos R and Boroyevich D 2012 Total flux minimization control for integrated interphase inductors in paralleled, interleaved three-phase two-level voltagesource converters with discontinuous space-vector modulation. IEEE Trans. Power Electron. 27(4): 1679-1688

[26] Hari V S S P K and Narayanan G 2012 Space-vector-based hybrid pulse width modulation technique to reduce line current distortion in induction motor drives. IET Trans. Power Electron. 5(8): 1463-1471

[27] Hou C C, Shih C C, Cheng P T and Hava A M 2013 Common-mode voltage reduction pulsewidth modulation techniques for three-phase grid-connected converters. IEEE Trans. Power Electron. 28(4): 1971-1979

[28] An S L, Sun X D, Zhang Q, Zhong Y R and Ren B Y 2013 Study on the novel generalized discontinuous svpwm strategies for three-phase voltage source inverters. IEEE Trans. Ind. Inform. 9(2): 781-789

[29] Prasad J S S and Narayanan G 2014 Minimum switching loss pulse width modulation for reduced power conversion loss in reactive power compensators. IET Power Electron. 7(3): $545-551$

[30] Lee J S and Lee K B 2015 Carrier-based discontinuous PWM method for Vienna rectifiers. IEEE Trans. Power Electron. 30(6): 2896-2900

[31] Saritha B, Binojkumar A C and Narayanan G 2016 Experimental comparison of conventional and bus-clamping PWM methods based on electrical and acoustic noise spectra of induction motor drives. IEEE Trans. Ind. Appl. 52(5): 4061-4073

[32] Gendrin M, Gauthier J Y and Shi X L 2017 A predictive hybrid pulse-width-modulation technique for active-frontend rectifiers. IEEE Trans. Power Electron. 32(7): 5487-5496

[33] Das S, Binojkumar A C and Narayanan G 2014 Analytical evaluation of harmonic distortion factor corresponding to generalized advanced bus-clamping pulse width modulation. IET Power Electron. 7(12): 3072-3082

[34] Leonhard W 2001 Control of electrical drives. Berlin, Heidelberg: Springer-Verlag

[35] Hari V S S P K and Narayanan G 2013 A quick simulation tool forinduction motor drives controlled using advanced space-vector-basedPWM techniques. In: Proceedings of the National Power Electronics Conference (NPEC), Kanpur, India

[36] Venugopal S and Narayanan G 2005 Design of FPGA based digitalplatform for control of power electronics systems. In: Proceedings of the National Power Electronics Conference (NPEC), Kharagpur, India

[37] Vas P 1998 Sensorless vector and direct torque control. Oxford: Oxford University Press 